\title{
Boca de lixo: o outro, o nome e o encontro
}

\section{Boca de lixo: el otro, el nombre y el encuentro}

https://doi.org/10.34112/2317-0972a2018v36n73p33-49

Anelice Ribetto ${ }^{1}$

VAlter Filé

RESUMO: Este ensaio é um esforço para pensar o documentário Boca de lixo, de Eduardo Coutinho, como uma expressão estética que nos permite abordar os sentidos e os efeitos provocados por algumas das suas passagens e ampliar um dos conceitos com os quais trabalhamos há um tempo: o encontro. $\mathrm{O}$ encontro como espaço de conversação e como contorno metodológico possível para as pesquisas que interpelam a diferença e as relações de alteridade como questões para o campo da Educação. Para isso, ensaiamos algumas cenas de sentido. O Outro: o que há nele? e A pergunta e seus efeitos em nós: cenas que se ampliam a partir da abertura de um campo problemático e do conceito de encontro e suas condições de possibilidade para que a diferença seja mantida na sua radicalidade.

Palavras-chave: Outro; Eduardo Coutinho; diferença; cinema.

RESÚMEN: Este ensayo es un esfuerzo para pensar el documental Boca de Lixo de Eduardo Coutinho como una expresión estética que nos permite abordar los sentidos y efectos provocados por algunos de sus pasajes y ampliar uno de los conceptos con el que trabajamos hace un tiempo: el encuentro. El encuentro como espacio de conversación y como contorno metodológico posible para las investigaciones que interpelan la diferencia y las relaciones

1. Universidade do Estado do Rio de Janeiro, Rio de Janeiro, RJ, Brasil.

2. Universidade Federal Rural do Rio de Janeiro, Nova Iguaçu, RJ, Brasil. 
de alteridad como cuestión para el campo de la Educación. Para ello, ensayamos algunas escenas de sentido. El otro: qué hay en él? y La pregunta y sus efectos en nosotros: escenas que se amplían a partir de la apertura de un campo problemático y del concepto de encuentro y sus condiciones de posibilidad para que la diferencia sea mantenida en su radicalidad.

Palabras llave: Otro; Eduardo Coutinho; diferencia; cine.

No, no es "reconocer al otro"

El otro es anterior a todo reconocimiento. El otro ya es, ya está, ya estuvo antes de mí.

No, no es "descobrir al otro". No se juega a las escondidas así no más. No es "nombrar al otro" Es ser llamado por él. (Carlos Skliar, 2017, p. 165)

Nosso encontro com o documentário Boca de lixo (1992) se dá, fundamentalmente, através da problematização do que essa obra nos tem possibilitado, ao longo de alguns anos, nas discussões de nossos grupos de pesquisa no campo da Educação.

Somos professores que atuam na formação docente desde dois coletivos: o Coletivo diferenças e alteridade na educação e o Laboratório de estudos e aprontos multimídia: relações étnico-raciais na cultura digital. Ambos os espaços interpelam a diferença e as relações de alteridade, e é como parte dessa interpelação ao interior do que fazemos de nós que se forja esta produção.

Vamos tentar, neste esforço, pensar o documentário Boca de lixo, de Eduardo Coutinho, como uma expressão ética, estética e política que nos permite abordar os sentidos e os efeitos provocados por algumas das suas passagens e ampliar um dos conceitos com os quais trabalhamos há um tempo: o encontro. $\mathrm{O}$ encontro como espaço de conversação e como contorno metodológico possível para as pesquisas que interpelam a diferença e as relações de alteridade como questão para o campo da Educação. Para isso, ensaiamos algumas cenas de sentido. Cenas que se ampliam a partir da abertura de um campo problemático e do conceito de encontro e suas condições de possibilidade para que a diferença seja mantida na sua radicalidade. Uma primeira cena, que chamamos “O outro: o que há nele?", é enunciada a partir da entrada do documentarista no lixão e que é uma pergunta pela pergunta, que inaugura a possibilidade múltipla para um espaço habitualmente enunciado e dado 
a ver desde o já visto; a segunda cena, "A pergunta e seus efeitos em nós", problematiza o gesto de abertura para que o desconhecido não seja dado a ver desde uma referência, de uma massa, de uma generalidade, e sim desde a sua singularidade: se dar o próprio nome na relação de alteridade. Tratamos ainda de algumas questões surgidas do filme, como a produção de uma certa pedagogia do olhar que pode girar em torno dos encontros como possibilidades de estarmos (apenas) entre desconhecidos, conversando com desconhecidos e produzindo educação.

\section{UM CAMPO PROBLEMÁTICO SE ABRINDO: A BOCA DE LIXO}

Incialmente vamos a algumas especificidades, desde a escolha do filme até alguns elementos que envolvem a sua realização. Obviamente, ao escolher o filme escolhemos também o seu diretor (ou será que foi o contrário?). Nessa escolha do diretor, a partir do filme, tratamos ainda da sua forma de trabalhar, sua forma de pensar o mundo, sua forma de relacionar-se com o Outro. Então, muito do que vamos buscar no filme se espalha pela obra do autor, que conhecemos razoavelmente bem e um tanto de perto ${ }^{3}$. Na verdade, temos que fazer outros esclarecimentos sobre a nossa condição em relação ao filme, para pensar diferença e cinema. Por um lado, o cinema se oferece como uma produção estética com a qual temos contato, seja numa sala de cinema, seja em outras situações, em outros tipos de exibição, como é o caso do filme em questão, já que ele não participou de nenhum circuito de cinema. Portanto, nossa experiência, nossa relação com o filme é do acompanhamento que vai desde o período da sua realização até a participação em exibições, tanto em espaços públicos (que não eram de cinema no sentido tradicional) quanto em atividades educativas, em escolas ou em nossas práticas pedagógicas. Tivemos oportunidades, portanto, de assistir a ele, de discuti-lo algumas vezes. Isso não quer dizer que o tenhamos esgotado, pois a cada vez o filme nos coloca diante de uma nova possibilidade de ver, de uma nova experiência estética.

Como experiência estética o cinema nos convida à problematização do ato de ver, ou àquilo que Didi-Huberman (1998, p. 30) chama de“inelutável cisão do ver”. Diz ele: "O que vemos só vale - só vive - em nossos olhos pelo que nos olha. Inelutável porém é a cisão que separa dentro de nós o que vemos daquilo que nos olha”. E mais

3. Valter Filé trabalhou com Eduardo Coutinho no Centro de Criação de Imagem Popular - Cecip. Esteve próximo da produção de Boca de lixo. Sua condição de proximidade com o diretor criou, de certa forma, a possibilidade também de proximidade de Anelice Ribettto. 
adiante, sugere que "devemos fechar os olhos para ver quando o ato de ver nos remete, nos abre a um vazio que nos olha, nos concerne, e, em certo sentido, nos constitui" (p. 31). Podemos dizer que a relação diferença e cinema - e por consequência aquilo que essa relação pressupõe como encontro com o Outro, como relação de alteridade depende de uma espécie de jogo de olhares: vemos o filme, mas ele também nos olha, complexificando fortemente o papel do "eu" e do "Outro". Os "espaços em branco", os "vazios" forçam a complexificação desse jogo de olhares, desse jogo alteritário. Como diriam Hilgert e Fischer (2016, p. 1240, grifo nosso),

filmes com mais espaços "em branco", com mais lacunas, são exatamente aqueles que mais nos convocam, que mais nos colocam dentro daquelas imagens e cenas, que nos tiram de nossa posição estável, para ocupar o lugar incerto e desconhecido do outro. Em suma, são esses vazios que nos olham.

O que nos olha - os vazios, as lacunas - nos é interpelado pelo filme, mas de forma singular, desde que o filme nos dificulte a conclusão, a moral da história. Que ele se abra para nos pensarmos, para pensarmos o Outro e, principalmente, o Outro em nós.

Reafirmamos, então, que a escolha do filme em questão se deu em função das várias possibilidades que ele nos ofereceu para pensarmos os encontros e os riscos de tais encontros: os processos de alteridade e os riscos de invenção do outro como clichê, do que já é conhecido, do que já é sabido. Acreditamos que neste documentário (e nos demais do diretor) Eduardo Coutinho trabalha arduamente para fugir das armadilhas da obsessão pela confirmação daquilo que ele já sabe (sobre o Outro?). Nos seus filmes nos têm chamado a atenção os dispositivos colocados em circulação para tirar o sossego do espectador - e dele mesmo -, para livrá-lo dos perigos do "não tenha nada com isso!". O diretor tem nos sugerido aproximações com ideias de Carlos Skliar: aquilo que vemos no Outro parte de algo que já está em nós. Então, o encontro com o Outro necessariamente implica o eu, a importância que o eu, de qualquer forma, terá naquele contato. Skliar (2003, p. 121) diz: "O outro só é outro se puder ser capaz de mostrar-me, claro que sempre a uma distância prudente, quem somos nós e quais ajustes devemos fazer para parecermos, cada vez mais, nós mesmos". "E se o outro não estivesse aí?", pergunta radicalmente o autor - já no título - em um dos seus livros.

Boca de lixo foi escolhido, também, por algumas especificidades: pelo fato de ele ter sido produzido em vídeo (em suporte de fitas, ou seja, não digital) - e, desde aí, abrigar todos os perigos em relação ao mundo do cinema (do ponto de vista 
tanto da qualidade da imagem quanto das dificuldades de uma edição linear, da deterioração do material e das possibilidades de exibição em telas grandes). Mas o que mais nos chamou a atenção foi a sua produção - ou a falta dela. Boca de lixo não permitiu que o diretor se valesse de alguns dos seus "métodos". Não permitiu que ele se preparasse. Coutinho não criou uma proposta para um documentário num lixão. Ele topou com o lixão!

Ele rodava uma outra produção e, quase por acaso, encontrou o vazadouro de lixo, em São Gonçalo, Rio de Janeiro. Foi um acontecimento, um achado! Sendo assim, não houve uma pré-produção com pesquisa, montagem de equipe, orçamento discutido, etc. As pessoas que trabalhavam na outra produção foram convidadas a participar, apesar das dificuldades de orçamento. $O$ filme seria feito com o aproveitamento das "sobras" de outra produção.

O filme nos mostra, então, um homem que entra no seu campo problemático - a vida daquelas pessoas naquele lugar - para encontrar-se com elas, tendo que preparar-se, que ajeitar-se, enquanto agia, enquanto filmava. Uma aposta a seguir, pelo que coemerge no campo, que só é possível de acontecer, se quem habita esse território se mantém atento ao presente.

Assim Coutinho resolveu ir ao encontro daquelas pessoas. Levava aquilo que ele considerava essencial para o seu trabalho: a necessidade de um "enclausuramento", ou seja, instalar-se num espaço fechado, circunscrito durante um determinado tempo, com a incerteza sobre a possibilidade de realização do filme, não apenas em função da sua condição, mas porque, segundo ele, sempre é possível que o filme não aconteça, por mais que se tenha pesquisa, que se tenha um certo domínio do que se pode fazer, etc. Porque tem o Outro. Porém, Coutinho sempre tem uma atenção intensa aos movimentos de negociação entre os dois lados da câmera. E uma fé muito grande na possibilidade do encontro, mesmo com todos os riscos que rondam uma temática complexa quando se fala sobre miséria, sobre pobres, sobre lixo e sobre as pessoas que supostamente comem daí, vivem sob essas circunstâncias. E, consequentemente, conclui-se que já se sabe, já se conhece o que vem do filme.

Consuelo Lins, em seu livro $O$ documentário de Eduardo Coutinho - televisão cinema e vídeo (2004, p. 87), comenta o seguinte:

O tema desse documentário não poderia ser mais difícil, porque lida com o clichê da pobreza brasileira: restos da civilização industrializada do Ocidente, periferia da periferia dos países ricos, quinto mundo, fim do mundo. As primeiras imagens se assemelham 
a um filme de ficção científica, daqueles em que o futuro é apenas a intensificação do que há de mais caótico no presente: porcos atolam em restos, um cachorro esquelético revolve detritos, um cavalo branco mastiga alguma coisa em meio a uma névoa que paira sobre um deserto de lixo, um bando de urubus voa sobre o lixão. No plano seguinte defrontamos o pior, na imagem e no som - até então praticamente inexistente o "bicho-homem" entra em cena, em bando, todos falando ao mesmo tempo. Com enxadas, pás e ancinhos investem sobre o lixo que acaba de ser despejado do caminhão, em uma imagem que provoca mal-estar e repulsa: repulsa de fazer parte de uma sociedade que produz cenas de crianças, adultos, velhos chafurdando no lixo para comer, o que para dizer o mínimo, é constrangedor; mal-estar de se deparar com tal estado de degradação.

Complementando as observações da autora sobre as cenas de abertura, um elemento nos pareceu importante. Antecedendo a entrada em cena do "bicho-homem”, um plano aberto, meio que na contraluz, urubus e outras aves caminham, voam. Uma fumaça - que serve como um efeito - reforça o ar ficcional. Pareceu-nos, na primeira vista, uma locação, qualquer locação. Um lixão, qualquer lixão num mundo que talvez não exista para muitos de nós, que talvez não tenha proximidade conosco. De repente, numa das imagens, vislumbramos ao fundo o Cristo Redentor. Imagem icônica do Rio de Janeiro em todo o mundo. Que aproximações, que sentidos e sem sentidos são pensáveis entre esses "dois" mundos? Tivemos a sensação de que alguma coisa que nos protegia tinha sumido com tal aparição. Aparição que, de alguma forma nos colocava, talvez não na cena do lixo, mas nos tornava contíguos espacialmente, implicados. Da imagem do cartão postal do Rio de Janeiro, algo nos olhava, como diz Didi-Huberman (1998).

O documentário começa como se houvesse uma cena montada com cuidado, com som ambiente reforçado por outro som que fora adicionado ${ }^{4}$. A abertura causou muito desconforto nas apresentações de que participamos. Em algumas delas, pessoas se negavam a continuar assistindo, pois alegavam que não estavam dispostas a mais uma exploração da miséria alheia como espetáculo. Outras diziam que tinham pena daquela gente miserável e não estavam dispostas a ver o sofrimento delas. Como diz Lins (2004, p. 88), é "como se o filme jogasse na nossa cara a imagem que temos desses seres, a imagem do senso comum. O documentário 'não apenas se confronta com essa questão como a traz para o seu interior”."

4. Trilha sonora de Tim Rescala. 
O que há para dizer sobre os miseráveis que vivem no lixo e do lixo? Talvez fosse essa a pergunta implícita, depois da cena de abertura do filme. Coutinho, então, empreende uma luta contra todos os riscos dos clichês, daquilo que já se sabe, daquilo que supostamente já se conhece. $O$ cineasta aposta suas fichas e parte para o encontro. Vale ressaltar que o diretor não trabalha com temas gerais, como, por exemplo, lixo, pobreza, miséria, etc. Sua fé está colocada no encontro, nas possibilidades de conversar com desconhecidos, para que eles lhe falem sobre como veem o mundo, como se inventam em tais conversas e as suas razões (FILÉ, 2000).

\section{O ENCONTRO}

$\mathrm{O}$ encontro tem como ponto de partida o olhar. Aquilo que divisamos e que o nosso olhar vai ajudando a forjar como posições, produzindo disposições. O olhar define a maneira de nos colocarmos no mundo e em relação ao que se olha. Subsidia a forma de nos colocarmos em/na relação com o Outro. Sabemos que o olhar não é coisa dos olhos, dos órgãos de visão, apenas. O olhar - e os julgamentos - dependem da nossa subjetividade, e isso explica por que não vemos as mesmas coisas e nem vemos do mesmo jeito. Antes mesmo dos corpos se encontrarem, antes mesmo de tentarmos uma comunicação qualquer, o olhar vai definindo as condições- nunca definitivas - do encontro. Muitos documentaristas, quando vão ao encontro de grupos sociais considerados "menos favorecidos" olham, produzindo uma certa hierarquia moral. Ou seja, lidam com o outro como se o outro fosse sujeito de determinados equívocos, ou, o que pode ser pior, como se o outro fosse a fonte de toda a verdade, de toda a luz. São aqueles que querem, com o seu cinema, transformar o mundo e, segundo Coutinho, começam transformando os personagens, ou ainda, inventando-os da forma que melhor confirme ou negue aquilo que se quer com o filme. Segundo o cineasta, talvez haja uma saída entre idolatrar o povo ou desprezá-lo. Talvez haja a possibilidade de se estar aberto ao Outro, de deixar-se surpreender.

Boca de lixo sugere uma disposição de seu diretor para surpreender-se com o Outro: a tentativa de estar vazio. E o que seria estar vazio? "Vazio é o seguinte: a pessoa tem que sentir que você não espera nada dela, nem resposta que sim nem que não. Tem um vazio que ela tem que preencher. Então é um vazio curioso que quer saber dela, entender o que ela tem para dizer." (FILÉ, 2000, p. 79).

$\mathrm{O}$ cineasta parece saber o que está em jogo nos encontros. O que está em jogo quando ele invade o espaço das pessoas com uma câmera, com uma equipe de 
gravação. Um grupo de pessoas que vêm de fora, que trazem um instrumento muito conhecido de todos: a câmera de vídeo (que naquele momento era indisfarçável pelo seu tamanho e pelas condições de operação). A câmera e as consequências daquilo que ela produz e coloca em circulação na mídia. Talvez, para muitas pessoas, a câmera seja considerada não pela sua condição em si, mas pelos efeitos e repercussões que produz. Repercussões nem sempre favoráveis aos que são retratados, $\mathrm{e}$ isso as pessoas de um modo geral sabem muito bem.

Existe instaurada, desde já, uma relação de poder. Dissimular essa relação não está em questão para Coutinho. Ao contrário. Ele alerta:"Na verdade, antes de filmar ou durante a filmagem eu nunca digo 'eu sou igual a você, tá?'. Eu não me visto de farrapos para falar com mendigos, eu não finjo que sou nordestino para falar com nordestinos" (FILÉ, 2000, p. 74).

Talvez essa afirmação da diferença como afirmação ética, estética e política da consideração do Outro pudesse produzir a condição de uma coexistência nos encontros. Um entre como condição micropolítica "não trabalhamos juntos, trabalhamos entre dois: negocia-se"(DELEUZE; PARNET, 1996, p. 28).

Eduardo Coutinho tem afirmado que o seu trabalho se dá a partir do encontro com as pessoas. Encontro esse mediado por câmeras e microfones. Os encontros são espaços-tempos cuidados, pois antes de qualquer produção existe uma pesquisa prévia sobre as suas condições, sobre as possibilidades de uma boa conversa. Neste estudo levamos em consideração, primordialmente, a riqueza com que a pessoa conta sua vida, muito mais do que o fato de a pessoa ter uma vida muito interessante, se não souber contá-la bem. Isso não quer dizer que os encontros sejam repetições, para o diretor, daquilo que já havia sido captado pelos pesquisadores - já que ele nunca entra em contato com os personagens antes da filmagem. Coutinho escolhe bons narradores. A gravação, o encontro, é sempre um acontecimento, na medida em que ele não escolhe fazer um roteiro para entrevistar as pessoas, mas utiliza-se das artimanhas e de dispositivos que possam levá-los a uma boa conversa. Uma conversa que sempre será encaminhada por negociações. Negociações que se dão no entre (os dois lados da câmara?). Artimanhas e dispositivos criariam, de certa forma, sua erva, nas margens, imperceptivelmente fazendo com que, de certo modo, o que produz o filme sacuda seu modelo (DELEUZE; PARNET, 1996).

Contar um pouco da forma de produção dos documentários de Coutinho tem como objetivo ampliar o grau de dificuldade vivido por ele e sua equipe. Como já mencionamos aqui, o diretor achou casualmente o vazadouro e, de cara, resolveu 
que queria ouvir as pessoas que viviam, que trabalhavam ali. Sem pesquisa, sem garantias, ele foi falar com elas. Ele foi tentar uma aproximação, encontrar-se para uma conversa. Encontrar-se com quem? Quem são essas pessoas?

Ele começa as filmagens. A tentativa de uma aproximação é rechaçada veementemente. Vemos pessoas que fogem da câmera, usam camisas para cobrir seus rostos como uma espécie de passa montanhas. Um rapaz chega a questionar o diretor: "O que vocês ganham com isso, pra ficar botando isso na nossa cara?". Não queriam aparecer, ou melhor, não queriam ser a confirmação daquilo que já se sabia deles. Sabiam - e algumas pessoas verbalizam isso durante o filme - o modo como a mídia de uma maneira geral tratava pessoas em tais condições. Eles só serviam, em tais circunstâncias, para ilustrar matérias ou para serem pano de fundo de alguma tese sobre a realidade brasileira, sobre o capitalismo, sobre a miséria, sobre a vida dos pobres, sobre a desigualdade. Eles sabiam que na mídia eles eram apenas uma generalização, não eram pessoas, não tinham uma vida, não tinham história.

Coutinho vai insistindo numa aproximação nas cenas seguintes. Ninguém quer falar, com medo do destino das suas falas e das suas imagens. O que eles já sabem do diretor, como encarnação de uma prática jornalística. Coutinho diz que resolveu fazer o documentário, porque na primeira vez que ele apareceu lá havia pessoas "fritando ovo, jogando futebol, namorando... Ou seja, eles estavam vivendo isso daí a quatrocentos anos. Eu não quero saber o que eu, o que nós pensamos deles"(COUTI$\mathrm{NHO}, 2009,2$ ':13”). O que eles dizem (e fazem), segundo o diretor, são estratégias de sobrevivência, e isso lhe interessa.

Depois do primeiro dia de rechaço, a equipe voltou ao lixo. Talvez essa volta tenha colocado algumas dúvidas na cabeça das pessoas. Talvez tenham começado a pensar que alguma coisa naquela equipe era diferente. Normalmente as matérias para o telejornalismo são filmadas rapidamente. Já se sabe o que se quer que se diga, já se sabe de que tipo de imagem se precisa para ser colocada como fundo para determinado discurso. É prática de produção de mesmidade. Gravam rápido e vão embora. Mas, agora, as pessoas talvez tenham ficado intrigadas pelo fato de essa equipe ter voltado. Voltar talvez significasse uma espécie de atenção mais demorada, uma certa importância sobre alguma coisa que talvez nem eles soubessem direito, pois, para dizer aquilo que normalmente se diz do lixão e das pessoas que trabalham lá, não era necessário mais do que alguns minutos. Mas a equipe voltara. A equipe atendeu ao que a própria atenção ao presente produziu: a coemergência de alguma outra coisa 
ainda não pensada e não filmada. Uma atenção que, talvez e paradoxalmente, fosse aquela que nos permitisse entrar distraidamente em algum lugar.

Distraidamente, quer dizer, como uma atenção tensionada ao máximo, mas se mantendo como atenção pura, como uma tensão que não está normalizada pelo que sabemos, pelo que queremos, pelo que buscamos ou pelo que necessitamos. O ouvido [a volta da equipe] fino, atento, delicado, aberto à escuta, o ouvido [equipe] distraído, seria aqui uma cifra da disponibilidade. (LARROSA, 2004, p. 38)

Aos poucos as pessoas começaram a aceitar a presença da câmera naquele cenário.

UMA CENA: O OUTRO - O QUE HÁ NELE?

Lo absolutamente Otro es el Otro. No se enumera conmigo. La coletividad en la que digo "tú" o "nosotros" no es un plural de "yo". Yo, tú no son aqui individuos de un concepto común. Ni la posesión, ni la unidad del número, ni la unidad del concepto me incorporan al Otro. Ausencia de patria común que hace del Otro el extranjero; el extranjero que perturba el "en nuestra casa". Pero extranjero quiere decir también libre. Sobre el no puedo poder. (LÉVINAS apud SKLIAR, 2017, p. 81)

Esse não "no puedo poder" se materializa, ao nosso entendimento, quando o diretor diz que pretende ir ao encontro vazio. Não é aquilo que ele supostamente sabe que vai possibilitar o encontro, mas a disponibilidade para ouvir o Outro em sua estrangeiridade, como nos diz acima Lévinas.

Coutinho sabe que todo encontro depende de negociações. Ele não as esconde, ao contrário. Em alguns de seus filmes mostrou uma pessoa da produção pagando os entrevistados 5 . Tal fato, que poderia não estar no filme, causou algum estranhamento. Como se o pagamento pudesse inserir uma espécie de dúvida sobre a espontaneidade dos depoimentos. São negociações, não apenas de desejos, mas também de coisas materiais e concretas.

5. O filme Santo Forte (1999) precisava ser realizado num determinado espaço de tempo. Para garantir que as pessoas estivessem nos dias indicados, resolveu-se pagá-las. 
Nas negociações para a realização do filme aparecem pessoas se negando a participar. Fogem, se escondem da câmera. O filme abriga os testemunhos da sua negociação. Uma dessas negociações que nos pareceram importantes se dá depois de muito rechaço. Exatamente quando o diretor pergunta pelo nome das pessoas. Pergunta para uma menina se ela conhece as pessoas que estão ali. Ela diz que sim, pois foi criada junto com muitos deles. E começa a dizer o nome das pessoas. Outras vozes se apressam em identificar os demais. E convocam as pessoas, nomeando-as: "Pedro, Sara, Rosana, Diméia, Eduardo, Néi...". Acreditamos que esse foi um aspecto negociado: a alteração da condição de participação daquelas pessoas. Não seriam mais "populares". Agora seriam pessoas que atenderiam pelo nome próprio.

O nome problematiza o gesto de abertura para que o desconhecido não seja dado a ver desde uma referência e sim desde a sua singularidade: dar a conhecer $o$ próprio nome na relação de alteridade. Talvez o nome seja aquilo que permite ao desconhecido continuar sendo desconhecido, mas numa intenção de aproximação possível (o nome como encontro? Como o que forja o entre?). No filme os nomes funcionaram como uma possibilidade de aproximação, pois é o nome (como invento de sentido) que nos forja sujeitos de desejos. A pergunta então se desloca: já não nos interessa (e acreditamos que a Coutinho também não) quem é o outro como uma questão que interpela apenas a sua condição de categoria identitária, mas o que há no nome do outro? Quais as lutas pelos sentidos e os efeitos na vida das pessoas que se travam no nome? A pergunta pelo nome produz um deslocamento para o que se produz entre (nós): qual é seu nome? (que, sendo próprio, lhe foi, primeiro, outorgado por outro).

Aquelas pessoas não são mais corpos indistinguíveis que se deslocam naquele cenário incômodo. Não são mais "catadores de lixo", apenas, na sua generalidade. Agora têm nomes: Nirinha, Lúcia, Cícera, Enock (também chamado de Papai Noel), Jurema. Os corpos dessas pessoas, constituídos pelos nomes próprios, os torna únicos, singulares, produtores de sentidos. Eles podem ainda ter desconfiança, mas, talvez, exista já uma abertura para algo que está por vir.

As negociações foram além daquilo que já está estabelecido e mais ou menos consagrado pelas equipes de televisão: só têm nome e, portanto, só teriam créditos - nomes estampados nas telas - as "autoridades". Os demais, os sem nomes, muitas das vezes são chamados de "populares". Uma massa que só pode participar destas produções como algo que ilustre a fala das autoridades, dos repórteres sobre uma situação dada. Não interessam exatamente como pessoas, mas como o popular 
que pode dar algum aval para o que se diz sobre ele ou sobre algo que deve fazê-lo importante, para confirmar ou negar o que já se sabe.

O nome próprio convoca uma imagem materializada em um corpo. Coutinho, além do nome, também mostra os diferentes retratos, retirados dos closes feitos pela câmera de vídeo em outras gravações. Como afirma Consuelo Lins (2004, p. 88),

Esse gesto indica que o que está sendo proposto não é mais uma desapropriação da imagem alheia, segundo a lógica midiática, mas a criação de uma imagem compartilhada entre quem filma e quem é filmado, com riscos e possibilidades de equívoco. $O$ prazer de recuperar uma imagem, de se ver simplesmente duplicado, mesmo que precariamente, faz com que se estabeleça uma ligação entre filmados e filmadores - $\mathrm{e}$ faz com que o vídeo se realize.

Daí em diante é como se as pessoas percebessem que houve um trabalho, uma preocupação, uma atenção. Pois aqui, talvez, reverberem as perguntas que Skliar (2017, p. 172) nos faz: "¿Cómo suponer una figura de alteridade al margen de la relación que se estabelece y que estabelecemos con ella? ¿Es la alteridad pura individualidad o bien un entrecruzamiento caótico de figuras múltiples?". Talvez as pessoas tenham sentido que não eram mais apenas temas - os miseráveis do lixo, a última degradação humana, os heroicos sobreviventes de um inferno. Talvez agora eles possam ser singulares, contar suas vidas, dizer das suas razões, expor suas contradições, suas ambiguidades, suas fortalezas. Eles se olham nas imagens e vão identificando outros companheiros: cria-se um espaço de alegria.

Aqui, então, afirmamos que um bom encontro produz e se produz quando há o "cuidado do outro" como gesto de efeito desse encontro. Pensamos que isso aparece no filme: um cuidado que tem vinculação com a questão ética de fazer efetiva qualquer potência de agir e de compor com o mundo: o gesto de alegria é esse efeito.

A pergunta e Seus efeitos (em nós)

Boca de lixo tem um momento em que nos coloca frontalmente com aquilo que inicialmente nos produziu um certo mal-estar. Diríamos mesmo um constrangimento. Uma pergunta feita pelo documentarista. Uma pergunta que, mais do que afetar ou trazer consequências para os entrevistados, na verdade, funcionou em nós como uma espécie de desalojamento dos lugares de conforto. Uma pergunta que 
talvez jamais ousássemos fazer numa pesquisa. Uma pergunta que, depois, se fez imprescindível para o documentário e fatal para compreendermos o que significa o "desconhecimento" do outro - o desconhecimento da sua moral, dos seus sentidos e sem sentidos para com as coisas mundo. $\mathrm{O}$ desconhecimento das suas razões. Uma pergunta em que o diretor reafirma a sua intenção de não falar pelo Outro - o que não é o mesmo que não falar, não colocar-se -, de não antecipar ou de resistir à tentação de invocar no Outro aquilo que gostaria de ouvir. Uma pergunta que nos deu uma sensação de desamparo.

De forma natural, sem rodeios, sem explicações, sem desculpas ou justificativas, ele perguntou: "É bom trabalhar no lixo ou não?". Como, em meio a um cenário tão miserável, tão radicalmente inóspito, tão degradante, pode ser possível tal pergunta? Ela, a pergunta, resvalava, na nossa compreensão, em uma atitude cruel, talvez até sádica. Esse nosso sentimento nos acompanhou até as respostas. As respostas - essas ou a outras questões em torno da comparação "melhor/bom x pior/ruim" - nos surpreenderam. Surpreenderam, não pelo seu conteúdo, apenas, mas, principalmente, pela opção daquilo que faria parte da produção da resposta. Ou seja, para uma pergunta dicotômica, supostamente, a escolha de uma das opções oferecidas. Supúnhamos respostas curtas e obedientes.

A pergunta abriu uma dimensão que tínhamos dificuldade em acreditar que existisse. Uma abertura para o Outro, para o trabalho, em nós, de que ele é um verdadeiro Outro. A pergunta possibilitou respostas que sugerem outras complexidades sobre a desigualdade brasileira, mesmo quando, de saída, ela nos parecera ser dicotômica e oferecer pouco espaço para a movimentação do pensamento dos participantes. Outra coisa que nos chamou a atenção foi que nenhum dos entrevistados se indignou com tal pergunta, como poderíamos supor. Talvez essa suposição, esse tipo de "conhecimento" de como o Outro deveria se comportar é que nos faz censurar, eliminar a possibilidade de certas questões, de certas perguntas.

A pergunta abre uma problematização sobre um dispositivo que opera nas nossas pesquisas e que conseguimos enxergar produzindo efeitos no documentário. Aquilo que Skliar nos ajudou a definir como "conversas entre desconhecidos", como aquilo que faz alguma coisa se chamar de Educação e que, necessariamente, implica, talvez, um "encuentro de fragilidades".

Nos tornamos tão conhecidos, que descontando os cumprimentos de ocasião, já ninguém conversa com ninguém. Deixar de conversar é um dos tantos desenlaces do 
conhecimento entre as pessoas. Não falar-se, não ter nada para dizer. Como se conhecer fosse já saber tudo, sem saber nada. O implícito sem matizes ou texturas. A declaração do abandono, o final das perguntas, o abster-se das intrigas, o suicídio da curiosidade, da compaixão por outras vidas. (SKLIAR, 2017, p. 173)

O que seria uma conversa entre desconhecidos? Seria, talvez, uma possibilidade de tentarmos encontros, não desde aquilo que já supomos como sabido, como conhecido, mas desde aquilo que, como nos diz Skliar, não temos. Talvez seja a criação das condições de possibilidade para que o nosso olhar, ao divisar o Outro, ao dar a partida para o encontro, considere esse Outro como aquele de quem não se sabe e que, talvez, jamais se vá saber. Boca de lixo, em relação àquelas pessoas, é um retrato comovente, um drama humano, sem a pretensão de dar lição de moral, de consertar o mundo.

O filme se presta a uma experiência (a nossa experiência) em que o olhar, que é condicionado pela manifestação da nossa subjetividade e não uma operação que diz respeito simplesmente ao órgão de visão, ou seja, o olhar como um gesto nos ajuda a pensar nas diferentes formas de olhar o encontro com o Outro, naquilo que, problematizando o já conhecido que está em nós, se abre para a pura tensão do desconhecimento que há entre nós. Na verdade, ele nos ajuda a olhar o Outro em nós. E, como todo filme - naquilo que ele dá a ver -, como toda fotografia, como toda imagem, ele é uma pedagogia do olhar. Mas uma pedagogia que nos ensina a insistência da incerteza, no caráter sempre em aberto e precário do nosso olhar, daquilo que vemos e das coisas do mundo que nos olham. Uma pedagogia que, mais do que nos ensinar a olhar de forma certa, nos ensina o que devemos ver, para onde e para que devemos olhar. Para nós, o filme nos oferece a sua própria condição de incerteza: o olhar do filme sobre o próprio filme. O olhar do filme sobre o próprio diretor.

O olhar do filme sobre a própria ação do diretor no encontro com as pessoas do lixão dá a ver não apenas com os olhos, a partir das imagens. O olhar do filme transparece nas falas que se buscam (ou buscariam aquilo que talvez ainda não esteja em nós?), algumas vezes se desencontram. Como Coutinho afirma, ele faz filmes para "ouvir" as histórias das pessoas, o que as pessoas pensam do mundo, ou seja, ele pretende compreender as razões do Outro. Sem necessariamente concordar. Um exercício de diferir como prática de alteridade. Para quem conversa e difere, a palavra é mobilizadora fundamental das negociações, das tensões dos encontros, e 
nossa impressão é que a palavra monta o filme $e^{6}$. A montagem é uma das formas de pensarmos sobre as possibilidades de olhar e escutar.

Uma das partes importantes de um filme com relação a sua condição de pedagogia do olhar é a montagem, a edição. No caso do diretor, ele tenta fugir da "montagem invisível"7. Além da opção pelos "cortes secos", ele constantemente está na cena, inserindo-se, colocando-se e, muitas das vezes, expondo-se, fragilizando-se. Deleuze acredita que o cinema mostra os métodos e o pensamento que movem os cineastas na realização dos seus filmes. Em Cinema - a imagem movimento (1983), Deleuze descreve a montagem no cinema clássico. Destaca que o modo como os planos são encadeados pretende criar uma sensação natural de movimento. Boca de lixo está mais para o cinema moderno, como nos diz Consuelo Lins na obra citada (2004, p. 96):

Coutinho é herdeiro do cinema moderno, na sua ruptura com aquilo que o cinema clássico, ao longo da sua existência, acostumou o espectador: finais felizes, desenlaces protetores, saídas esperançosas. Roma, cidade aberta (1945), de Roberto Rossellini, é um dos primeiros filmes a produzir um expectador "desassistido", a quem não é dado qualquer conforto moral, forçado a ter que recuperar sua capacidade de pensar diante do intolerável.

O documentário encaminha-se para o final, mostrando imagens das pessoas se vendo no vídeo já montado. Veem-se na tela, riem, ficam sérias, comentam. São pessoas, são trabalhadores. Crianças, idosos, homens e mulheres que contaram suas histórias e agora, de alguma forma, avaliavam a responsabilidade ética do diretor com suas imagens, com suas dignidades. $\mathrm{O}$ vídeo termina com imagens de seres humanos na tela.

Terminamos este texto, "desassistidos”, com a fala de um dos personagens do documentário, Enock. Ele diz: "O final do serviço é o lixo... E é dali que começa".

\section{REFERÊNCIAS}

DELEUZE, G. Cinema - a imagem-movimento. São Paulo: Brasiliense, 1983.

DELEUZE, G.; PARNET, C. Diálogos. Lisboa: Relógio D’ Água, 1996.

6. O documentário Santo Forte foi definido por alguns críticos como "a arte de filmar as palavras".

7. A "montagem invisível”: forma de sugerir uma continuidade "natural” das cenas que são justapostas. 
Boca de lixo: o outro, o nome e o encontro

DIDI-HUBERMAN, G. O que vemos o que nos olha. São Paulo: Editora 34, 1998.

FILÉ, V. Os dois lados da câmera. Entrevista com o documentarista Eduardo Coutinho. In: FILÉ, V. (Org.). Batuques, fragmentações e fluxos. Rio de Janeiro: DP\&A, 2000.

HILGERT, A. V.; FISCHER, R. M. B. Educação estética, cinema e alteridade. Cadernos de Pesquisa, v. 46, n. 162 , out./dez. 2016.

LARROSA, J. Linguagem e Educação depois de Babel. Belo Horizonte: Autêntica, 2004.

LINS, C. O documentário de Eduardo Coutinho - televisão cinema e vídeo. Rio de Janeiro: Jorge Zahar, 2004.

SKLIAR, C. Pedagogia (improvável) da diferença: e se o outro não estivesse aí? Rio de Janeiro: DP\&A, 2003. . Pedagogías de las diferencias. Buenos Aires: Noveduc/Perfiles, 2017.

\section{Filmografia}

COUTINHO, E. Boca de lixo. Rio de Janeiro: Cecip, 1992. Som, cor. Disponível em: <https:/ /youtu. be/wZcNU_Wy8Gk>. Acesso em: 12 ago. 2017.

COUTINHO, E. A entrevista como arte do encontro no docomentário. Visões do documentário.

Rio de Janeiro: Casa do Saber; Matizar, 2009. Cor. Disponível em: <https://www.youtube.com/ watch? $=$ ReVHCQoplro\&feature=youtu.be $>$. Acesso em: 12 abr. 2014.

RAMÍREZ,I. C. Ensayo audio-visual de "Hablar con desconocidos". Buenos Aires: Editorial Candaya, 2014. Som, cor. Disponível em: <https://vimeo.com/87029366>. Acesso em: 30 abr. 2016.

\section{SOBRE OS AUTORES}

Anelice Ribetto é psicóloga (Universidade Nacional de Córdoba, Argentina), Mestre e Doutora em Educação (Universidade Federal Fluminense). É Professora Associada da Universidade do Estado do Rio de Janeiro (UERJ), na Faculdade de Formação de Professores. Pertence ao quadro permanente do Programa de Pós-Graduação em Educação Processos Formativos e Desigualdades Sociais. E-mail: anelatina@gmail.com.

Valter Filé (José Valter Pereira) é Pedagogo, Mestre e Doutor em Educação (Universidade do Estado do Rio de Janeiro). É Professor Associado da Universidade Federal Rural do Rio de Janeiro (UFRRJ). É membro do quadro permanente do Programa de Pós-Graduação em Educação: Contextos Contemporâneos e Demandas Populares da UFRRJ e do Programa de 
Pós-Graduação em Educação da Universidade Federal Fluminense, ambos no estado do Rio de Janeiro.

E-mail:valterfile@gmail.com.

Recebido em 27 de janeiro de 2018 e aprovado em 22 de março de 2018. 